\title{
Foreign outsourcing and the product cycle: evidence from micro data
}

\author{
May 11, 2006 \\ Eiichi Tomiura \\ Department of Economics, Yokohama National University, \\ 79-3 Tokiwa-dai, Hodogaya-ku, Yokohama City 240-8501 Japan. \\ Phone: +81-(0)45-339-3563. Fax: +81-(0)45-339-3518. E-mail: tomiura@ynu.ac.jp.
}

\begin{abstract}
This paper provides empirical evidence on the product cycle and the firm's make-or-buy decision by using a firm-level data set with a direct measure of foreign outsourcing. Across industries, foreign outsourcing tends to be inactive in R\&D-intensive industries. Within each industry, products exported from the home country are on average significantly more R\&D intensive than those outsourced to independent foreign firms. Products manufactured within subsidiaries at South tend to have medium R\&D intensity. This ordering in R\&D intensity is consistent with the theoretical prediction.
\end{abstract}

JEL Classification: F23; F14; L22; L23

Key words: product cycle; foreign outsourcing; micro data

\section{Introduction}

The product cycle theory, originated in Vernon (1966), suggests that the production location shifts from industrialized North to low-wage South as the products become less R\&D intensive. Antràs (2005) adds the organizational dimension to this hypothesis by considering incomplete contracts, where outsourcing (contracted out to independent foreign subcontractors) is distinguished from insourcing (performed within multinationals by integrated subsidiaries) in Southern manufacturing. He predicts that "manufacturing is shifted abroad first within firm boundaries, and only at a later stage to independent foreign firms” (p.1054). However, as far as the author knows, the outsourcing across borders has not been investigated in previous 
empirical studies on the product cycle. As surveyed by Deardorff (1984) and Antràs (2005), previous research has been focusing either on exports or multinational's technology transfers. This paper provides rare firm-level empirical evidence on the relationship between R\&D intensity and product cycles, which are identified not only by export, offshore production within subsidiaries but also by foreign outsourcing, for all manufacturing industries in Japan.

The rest of this paper is organized as follows. Section 2 describes the data. The variations across industries are displayed in Section 3. The intra-industry, inter-firm variations are reported in Section 4. Concluding remarks are added in Section 5.

\section{Description of data}

The data used for this paper are derived from The Basic Survey of Commercial and Manufacturing Structure and Activity (Sho-Kogyo Jittai Kihon Chosa in Japanese). ${ }^{1}$ The survey covers 118,300 firms in all manufacturing industries without any firm-size threshold. Thus, this survey is a reliable representation of the entire Japanese manufacturing. ${ }^{2}$ As the survey was conducted only once at 1998, the data set is in a cross-section format.

As the unique and direct measure for foreign outsourcing, the survey asks sampled firms whether they contract out manufacturing/processing tasks to firms located overseas. ${ }^{3}$ The foreign outsourcing thus defined is explicitly distinguished from domestic outsourcing. ${ }^{4}$ Furthermore, the concentration on manufacturing/processing, excluding non-production services, in defining outsourcing is appropriate for discussing product cycle. The survey also contains a range of corporate variables, such as sales, employees, capital, R\&D expenditure, patents, exports, and foreign subsidiaries.

\section{Inter-industry comparison}


Based on published aggregate statistics of this survey, Figure 1 plots two-digit industries. The percentage R\&D-sales ratio is on the horizontal axis. The vertical axis measures the number of foreign outsourcing firms relative to the number of exporters, as the firms exporting products manufactured in the home country are supposed to be at an earlier stage in the product cycle.

As demonstrated in Figure 1, R\&D-intensive industries, such as chemical and machinery industries, are relatively inactive in foreign outsourcing, while industries actively outsourcing abroad, such as apparel, tend to spend limited expenditure on R\&D. This finding constitutes preliminary evidence favorable for the new product cycle theory. As intra-industry variations cannot be ignored, however, the next section investigates inter-firm comparisons.

\section{Inter-firm comparison}

By exploiting micro data, R\&D intensity is compared across different product cycles. While the product cycle is originally defined for each product, the micro analysis of this paper is at the firm level because product-specific data within individual firms are not available even when they manufacture multiple products. The regression results are reported in Table 1.

In the first two columns, the dependent variable is the percentage of $\mathrm{R} \& \mathrm{D}$ expenditure in sales. Though this measure is commonly used, we normally compare current vs. past R\&D activities in discussing the product cycle. To capture this implication in our cross-section data, the columns (3) and (4) normalize R\&D expenditure by the number of patents, since the denominator is likely to reflect the cumulative R\&D in the past. ${ }^{5}$

Included on the right-hand side of the regressions are the following three dummies corresponding to the product cycle: (a) North (exporting ${ }^{6}$ from Japan or producing within offshore subsidiaries $^{7}$ located at North), (b) In-South (producing within subsidiaries at South), and (c) F. Out (outsourcing to foreign suppliers). Since offshore subsidiaries of Japanese 
manufactures are predominantly located in Asia, U.S., or Europe, and since the survey contains no more detailed geographical disaggregation than Asia vs. the rest of the world (ROW), this paper interprets Asia as South and ROW as North. The baseline for comparisons is the firms involved in none of these global business activities.

While Vernon (1966) originally categorized offshore production as the second stage in the product cycle for the U.S. in his time, this paper combines exporters with firms producing in Northern subsidiaries, since Japanese firms producing in other advanced countries (U.S. or Europe) are likely to be similarly R\&D-active as firms producing exports in Japan. Besides, since FDI in North tends to be motivated by the proximity to markets rather than by low production costs, and since technologies used for production within subsidiaries are presumably well protected in North, the firms producing within subsidiaries at North should not be on average less $\mathrm{R} \& \mathrm{D}$ active than exporters. ${ }^{8}$

In addition to the product cycle dummies, the columns (2) and (4) also include (a) industry dummies at the most detailed 3-digit level, (b) firm size in sales, and (c) the firm's capital-labor ratio, to control for variations in R\&D intensity. ${ }^{9}$

In all cases in Table 1, foreign outsourcers are significantly less R\&D intensive than the firms exporting from domestic plants or producing within subsidiaries at North. The firms producing within subsidiaries at South tend to have medium R\&D intensity. The average $\mathrm{R} \& \mathrm{D}$-sales ratio in the initial stage of the product cycle (North) is more than three-percentage point higher than that in the outsourcing stage. The gap across product cycles is more substantial in the comparison of R\&D-patent ratio. Furthermore, this ordering is basically robust even after controlling for industry, firm size, and capital-labor ratio. Consequently, these firm-level findings are consistent with the product cycle theory by Antràs (2005) ${ }^{10}$ 


\section{Concluding remarks}

Antràs (2005) offers a theoretical prediction on the location as well as on the make-or-buy decision in the product cycle. This paper uses micro data covering all manufacturing industries in Japan to evaluate its empirical relevance. This paper has found that the ordering of R\&D intensity across product cycles is consistent with the theory. However, for a strict test in the future, one will need more detailed information, such as longitudinal product-specific data on foreign outsourcing.

\section{Acknowledgements}

The Ministry of General Affairs of Japan allowed the author to access the micro-data files by issuing official approvals. Kei Nara and Mutsuharu Takahashi were helpful for the access. This research was partly supported by Grant-in-Aid for Scientific Research C16530152. Remaining errors are mine.

\section{References}

Acemoglu, D., P. Aghion, R. Griffith, and F. Zilibotti (2004) Vertical integration and tec hnology: theory and evidence, downloadable at http://econ-www.mit.edu/faculty/do wnload_pdf.php?id=1041.

Antràs, P. (2005) Incomplete contracts and the product cycle, American Economic Review, 95, 1054-1073.

Deardorff, A. (1984) Testing trade theories and predicting trade flows, in Handbook of International Economics, Vol.1 (Ed.) R. Jones and P. Kenen, Elsevier Science, Amsterdam, pp.468-517.

Helpman, E., M. Melitz and S. Yeaple (2004) Export versus FDI with heterogeneous firms, American Economic Review, 94, 300-316.

Tomiura, E. (2005) Foreign outsourcing and firm-level characteristics: evidence from Japanese manufacturers, Journal of the Japanese and International Economies, 19, 255-271.

Vernon, R. (1966) International investment and international trade in the product cycle, Quarterly Journal of Economics, 80, 190-207. 
Figure 1 Inter-industry comparison

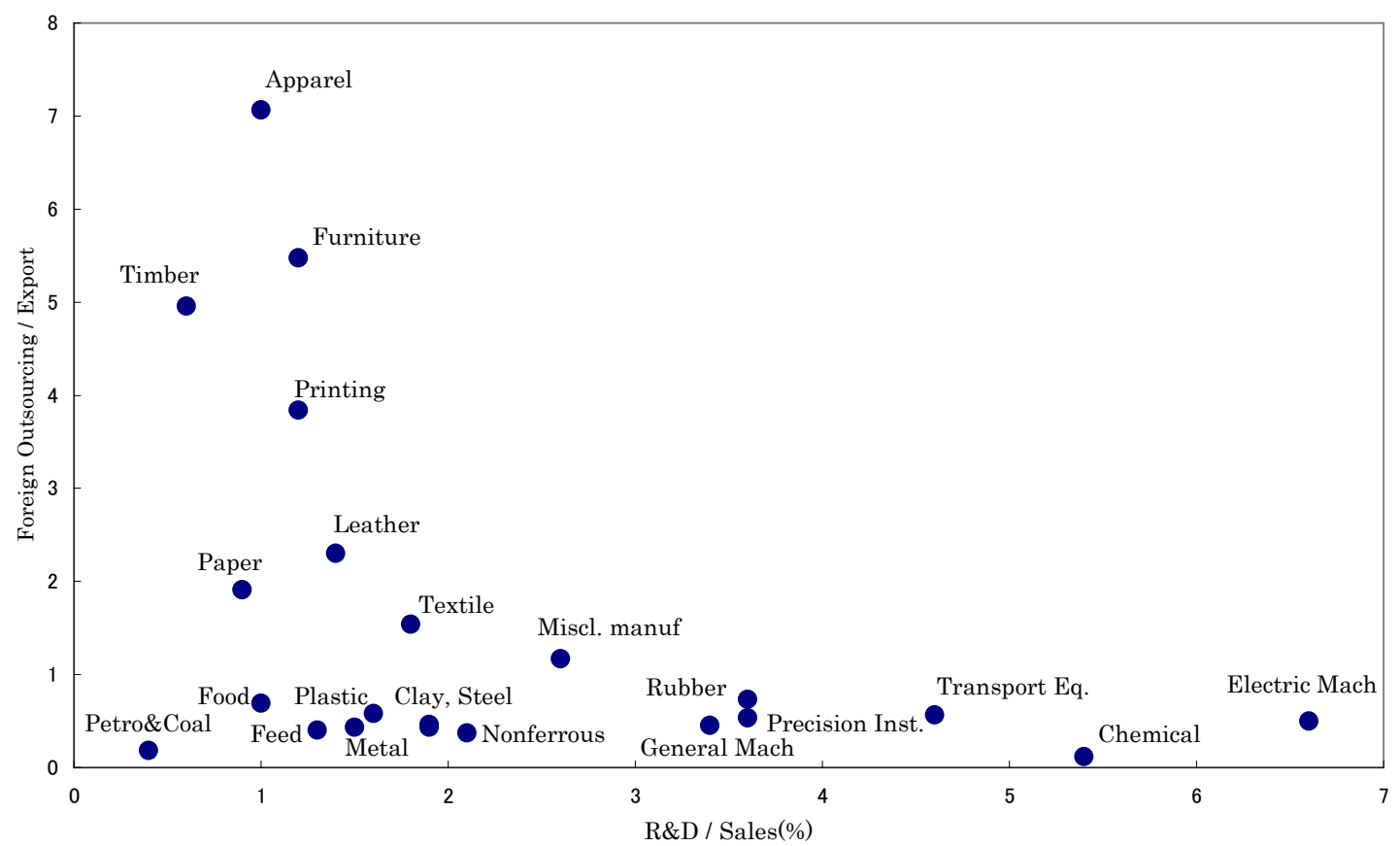

Notes) The vertical axis is in terms of the number of firms within each industry. All 2-digit manufacturing industries are plotted.

Table 1 Inter-firm comparison of R\&D intensity

\begin{tabular}{|c|c|c|c|c|}
\hline & (1) R\&D/Sales & (2) R\&D/Sales & (3) R\&D/Patents & (4) R\&D/Patents \\
\hline \multirow{2}{*}{ North } & 2.7659 & 2.7012 & 91.4703 & 84.0020 \\
& $(0.5297)$ & $(0.5304)$ & $(15.0654)$ & $(13.3169)$ \\
\hline In-South & -0.2859 & -0.5239 & 74.1897 & 48.9045 \\
& $(0.2564)$ & $(0.2382)$ & $(27.7191)$ & $(22.9813)$ \\
\hline F. Out & -0.3568 & -0.5404 & 0.3099 & -2.9502 \\
& $(0.0523)$ & $(0.0553)$ & $(5.4217)$ & $(6.8853)$ \\
\hline Other controls & No & Yes & No & Yes \\
\hline \# of Firms & 118,300 & 111,621 & 118,300 & 111,621 \\
\hline
\end{tabular}

Notes) Included as other control variables are 3-digit industry dummies, sales, and capital-labor ratio. Heteroskedasticity-robust standard errors are in parentheses. 
1 Though confidential firm-level data cannot be publicly disclosed, anyone can access to the same micro data as long as one obtains individual official permission from the government in advance.

${ }^{2}$ While all the firms with no less than 50 employees are surveyed, those with less than 50 are sampled with probability of less than one. However, this paper will control for the difference in firm size.

3 Tomiura (2005) explains the survey in detail and compares it with other outsourcing measures.

4 Though the survey does not separate Southern and Northern firms among foreign suppliers, the outsourcing to high-wage North is supposed exceptional.

5 To include a large number of firms owning no patents, this paper adds the value one to the number of patents before taking the ratio. One cannot adjust differences in economic value or depreciation across patents due to lack of data. $R \& D$ expenditure is recorded in million yen.

6 The firms are excluded from exporters if they record zero both in R\&D expenditure and in patents because the product cycle is not appropriately defined for these exporters.

7 Only majority-owned subsidiaries are included to concentrate on manufacturing affiliate as opposed to sales offices or portfolio-motivated FDI. The survey does not distinguish 100\% among majority ownership.

8 The model by Helpman et al. (2004) implies that firms producing within Northern subsidiaries must be on average more (not less) productive than exporters.

9 The capital-labor ratio is defined as tangible fixed assets divided by the number of regular employees. The firms without data on capital are excluded from the columns (2) and (4). 10 This result is also in line with other previous work. Acemoglu et al. (2004) report that outsourcing is more likely when the downstream industry is less R\&D-intensive, though they do not discuss the issue of location. 